\title{
SMART CONTRACT: THE CONCEPT, LEGAL NATURE, FEATURES OF CONCLUSION AND EXECUTION
}

\author{
Nizami Elmar ogli Safarli \\ Volgograd State University, Volgograd, Russian Federation
}

\begin{abstract}
Introduction: the paper is devoted to a new phenomenon in business activity in the conditions of IT development that contribute to the creation of secure contractual relations on the Internet on the basis of transactions executed through smart contracts. The author notes that the need for amendments that could fill the loopholes in the current legislation is obvious. And, first of all, it concerns Blockchain technology - the algorithm that mediates the safe development, conclusion and execution of smart contracts. Blockchain technology is considered in the paper as one of the safest means for concluding and executing smart contracts. The author argues that the study of the concept, legal nature and essence of smart contracts is relevant in the light of spreading their share in the total array of transactions in the world economy in conjunction with the changing domestic legislation governing the relevant sphere, as well as the international integration processes affecting the intensification of foreign economic activity of the Russian Federation. The smart contract concepts formulated by the Russian legislator in the process of upgrading the array of statutory regulation under conditions of economy digitalization are studied and compared. The features of conclusion and protection of the smart contract in the civil legislation of the Russian Federation are analyzed. In order to fully articulate the concept of the smart contract, reflecting its essence, functional purpose and legal nature, it is proposed to create a special law that would focus on the conclusion and implementation of "the smart contract" and the specification of the general norms of the civil code. At the same time, the norms of other special laws would supplement and correct the provisions fixed by this act depending on the sphere of managing and the legal regulation branch. The concept of the smart contract is formulated; its value for economic and contractual activity, and also the advantages and disadvantages of its application are established. The possible classifications of smart contracts are given.
\end{abstract}

Key words: business activity, contractual relations, electronic contracts, digital law, blockchain, cryptocurrency, smart contract, civil legislation.

Citation. Safarli N.E. ogli. Smart Contract: The Concept, Legal Nature, Features of Conclusion and Execution. Legal Concept, 2019, vol. 18, no. 4, pp. 54-60. (in Russian). DOI: https://doi.org/10.15688/lc.jvolsu.2019.4.7

УДК 34.347 .45

Дата поступления статьи: 25.07.2019

ББК 67.0 Дата принятия статьи: 25.08.2019

\section{СМАРТ-КОНТРАКТ: ПОНЯТИЕ, ПРАВОВАЯ ПРИРОДА, ОСОБЕННОСТИ ЗАКЛЮЧЕНИЯ И ИСПОЛНЕНИЯ}

\author{
Низами Эльмар оглы Сафарли \\ Волгоградский государственный университет, г. Волгоград, Российская Федерация
}

Введение: статья посвящена новому явлению в предпринимательской деятельности - смарт-контрактам (так называемым «умным договорам»), способствующим созданию безопасных договорных отношений в сфере Интернета и IT-технологий. Одним из самых безопасных средств заключения договоров является технология блокчейн, в рамках которой функционирует данный тип контрактов. Цель: рассмотреть и охарактеризовать понятие «смарт-контракт», определить его место в российском законодательстве. Методы: в работе использованы сравнительно-правовой метод, а также методы системности и анализа. 
Результаты: утверждается, что исследование понятия, правовой природы и сущности смарт-контрактов актуально в связи с распространением увеличением их доли в общем массиве сделок в мировой экономике. Изучаются и сопоставляются трактовки термина «смарт-контракт», сформулированные российским законодателем в процессе модернизации массива правового регулирования в условиях цифровизации национальной экономики; анализируются особенности заключения и охраны смарт-контракта в гражданском законодательстве РФ. Отмечается необходимость поправок, которые могли бы восполнить образовавшиеся в действующем законодательстве пробелы в отношении блокчейна в целом и смарт-контрактов в частности. Выводы: предлагается создать специальный закон, отражающий сущность понятия «смартконтракт», его правовую природу и функциональное назначение, а также ориентированный на заключение и реализацию «умного договора», конкретизацию общих норм Гражданского кодекса. При этом предполагается, что нормы иных специальных законов дополняли бы и корректировали закрепленные этим актом положения в зависимости от сферы хозяйствования и отрасли правового регулирования. Дается формулировка тремина «смарт-контракт»; отмечается его значение для хозяйственно-договорной деятельности, а также преимущества и недостатки применения. Приводятся возможные классификации смартконтрактов.

Ключевые слова: предпринимательская деятельность, договорные отношения, электронные договоры, цифровое право, блокчейн, криптовалюта, смарт-контракт, гражданское законодательство.

Цитирование. Сафарли Н. Э. оглы. Смарт-контракт: понятие, правовая природа, особенности заключения и исполнения // Legal Concept = Правовая парадигма. - 2019. - T. 18, № 4. - C. 54-60. - DOI: https://doi.org/ 10.15688/lc.jvolsu.2019.4.7

\section{Введение}

Развитие IT-технологий настолько стремительное, что сегодня затрагивает все сферы человеческой жизни, вследствие чего появляются, новые упрощенные способы ведения жизнедеятельности. Не осталось в стороне и право, упорядочивающее эти процессы. Юристов уже не удивляют такие слова, как «блокчейн» или «криптовалюта». Интернет-пространство вызывает все большее доверие как у простых граждан, так и у субъектов хозяйственной деятельности. IT-технологии способствуют созданию в Интернете безопасных предпринимательских правоотношений, договорной основой которых зачастую становятся сделки, в том числе оформленные посредством смарт-контрактов, так называемых «умных договоров». При этом договорные отношения развиваются гораздо стремительнее, чем нормы, направленные на их урегулирование, что, по утверждению специалистов, является следствием выполнения правом одной из важнейших функций - стабилизации [10].

В российском законодательстве договорное право основывается на достаточном массиве правовых норм, которые способны урегулировать порядок заключения, изменения или расторжения гражданско-правовых договоров, в том числе электронных. Гражданским пра- вом предусматривается определение природы и различных условий таких договоров. Однако процесс совершенствования договорного права с учетом развития IT-технологий и смартконтрактов неизбежен. Необходимость поправок, которые смогли бы восполнить образовавшиеся пробелы в действующем законодательстве, очевидна. Прежде всего это касается технологии блокчейна (Blockchain) - алгоритма, опосредующего безопасное развитие, заключение и исполнение смарт-контрактов.

\section{Характеристика технологии блокчейн}

Блокчейн - построенная по определенным правилам непрерывная последовательная цепочка содержащих информацию блоков. Данная технология интенсивно развивается на протяжении последнего десятилетия. Определение блокчейна впервые было дано в докладе Всемирного экономического форума: «Это технологический протокол, который позволяет обмен данными напрямую между различными договаривающимися сторонами внутри сети без необходимости посредников» [2]. В основе этой технологии заложена система распределенного ведения реестра, в которой отсутствует централизованное хранилище данных, что делает блокчейн одним из самых безопасных средств для хранения и передачи информации, а также совершения сделок и раз- 
личных операций, в том числе в сфере криптовалют. Помимо финансовой сферы блокчейн нашел свое применение и во многих других сферах деятельности, в частности в сфере интеллектуальной собственности.

\section{Понятие «смарт-контракт» в мировом законодательстве}

Понятие «смарт-контракт» распространилось по всему миру с небывалой скоростью и уже внедряется в российское законодательство. Ранее в законах не было аналога «умному договору», поэтому необходимость создания правовых мер, которые смогут обеспечивать его заключение и исполнение с учетом защиты интересов сторон, очевидна.

Идея смарт-контракта (smart contract) была сформулирована и предложена в 1994 г. ученым в области информатики, криптографии и права Ником Сабо [4]. Заключалась она в том, что описание всех условий «умного контракта» должно осуществляться с помощью математических инструментов и языков программирования. Непосредственно смарт-контракт Ник Сабо описывал в своих работах как электронный алгоритм, предназначенный для автоматизации процесса исполнения контрактов в блокчейне [12]. Однако практическая реализация такого контракта на том этапе развития технических возможностей была невозможна. Лишь в 2008 г. Сатоши Накамото предложил концепцию блокчейна, а практически ее реализовали только в 2009 году. В российском праве интерес к данному понятию возник всего несколько лет назад.

Принцип действия смарт-контракта заключается в следующем: содержание договора записывается в виде кода в компьютерной программе, отслеживающей и обеспечивающей исполнение обязательств. Стороны сделки прописывают в таком контракте условия, а также санкции за их невыполнение [11, с. 205-213].

Исследование понятия, правовой природы и сущности смарт-контрактов представляется актуальным, учитывая тенденции к их распространению в мировой экономике в совокупности с меняющимся отечественным законодательством, регулирующим соответствующую сферу, и международными интеграционными процессами, влияющими на ин- тенсификацию внешнеэкономической деятельности Российской Федерации.

\section{Понятие «смарт-контракт» в российском законодательстве}

Для того чтобы узнать, как формируется «умный договор», необходимо сделать отсылку на законопроекты, которые разрабатываются государством на сегодняшний день. В период с 2017 г. по настоящее время в законодательстве возникло несколько законопроектов, нацеленных на обеспечение охраны смарт-контрактов.

В законопроекте, предложенном Центральным Банком РФ, понятие «смарт-контракт» характеризуется как «договор в электронной форме, который определяет исполнение прав и обязательств путем совершения в автоматическом порядке цифровых записей в строго определенной им последовательности и при наступлении определенных им обстоятельств» [5]. Отметим, что данное определение является наиболее распространенным, однако, на наш взгляд, не в полной мере отображающим сущность смарт-контракта.

В проекте Ф3 «Об альтернативных способах привлечения инвестиций (краудфандинге)» понятие «смарт-контракт» схоже с понятием, закрепленным в проекте «О цифровых и финансовых активах». В нем также содержится уточнение, согласно которому при использовании смарт-контрактов возможно совершение действий, которые будут направлены на установление, изменение и прекращение прав и обязанностей участников инвестиционной платформы [6].

Характеристика смарт-контракта, которая предлагается в проекте Ф3 «О цифровых финансовых активах» [7] Министерством финансов РФ, является, по нашему мнению, усеченной и ориентированной на транзакции, однако для данного исследования необходимы расширенные понятия, нацеленные на заключение контрактов.

Таким образом, на сегодняшний день отсутствует нормативно закрепленное понятие «смарт-контракт». В попытке легализовать и законодательно закрепить его определение наиболее успешными представляются Центральный Банк РФ и Министерство финансов 
РФ. На наш взгляд, можно говорить о том, что смарт-контракт в гражданском праве является лишь условием договора о его автоматическом исполнении, а не сам договор.

\section{Особенности заключения и охраны смарт-контракта \\ в гражданском законодательстве РФ}

Анализируя вопросы правового регулирования заключения смарт-контрактов, необходимо обратиться к проекту, разработанному с целью внесения изменений в ГК РФ [8]. Согласно данному документу в ГК РФ необходимо ввести такие понятия, как «цифровое право» и «цифровые деньги».

Рассмотрим данные термины в непосредственной связи с заключением смарт-контрактов. В тех ситуациях, когда законом предусмотрено право на объект гражданского права (исключением являются нематериальные блага), сделка может быть заверена совокупностью электронных данных. В этом случае под совокупностью подразумевается цифровой код, которые расположены в электронной системе, отвечающей критериям децентрализованной информационной системы. Созданная информационная система обязана обеспечивать лицу уникальный код, позволяющий в любое время ознакомиться с описанием соответствующего объекта гражданских прав. Именно цифровой код будет являться цифровым правом в гражданском законодательстве.

Под цифровыми деньгами понимается совокупность данных в электронной информационной системе. Однако эта совокупность не удостоверяет право на какой-либо объект гражданского права, но способствует осуществлению платежей пользователями этой системы.

Следует уточнить, что к указанному проекту опубликована Пояснительная записка, в которой уточняется, что факт сделки, совершенной при помощи цифровых прав, в том числе смарт-контрактов, не оспаривается участниками [9]. Так, после регистрации и опознавания пользователей в системе, все их действия ведутся при помощи электронного алгоритма, а лицо, желающее приобрети данный объект или заключить сделку, получает свои права на данный объект при помощи наступления описанных ранее обстоятельств.
Следовательно, такая сделка происходит компьютеризовано, без каких-либо вмешательств той или иной стороны. В момент ее совершения цифровое право списывается у продавца и переходит покупателю, а деньги у покупателя и переходят продавцу согласно условиям, которые были заключены между ними. По общему правилу такое списание нельзя оспаривать (исключением является вмешательство в программу).

В момент заключения этого договора стороны должны осознавать результаты совершения своих действий и дальнейшие последствия. Так, воля на заключение договора включает волю на его исполнение.

Следовательно, законодатель уточняет, что иных норм, которые регулировали бы заключение смарт-контракта, не требуется, поскольку необходимые нормы уже существуюТ в ГК РФ.

Очевидно, что нормы ст. 420-434 ГК РФ нисколько не противоречат заключению смартконтрактов [3, с. 17]. Так, для заключения и обычных договоров, и договоров с применением IT-технологий необходимо соглашение двух или нескольких лиц, между которыми будет достигнуто соглашение по поводу существенных условий. Договор в любом из его проявлений, в письменной или электронной формах, будет заключен только с направления оферты одной стороной и ее акцепта другой. Статьей 434 ГК РФ также закреплено, что договор может быть заключен путем обмена электронными документами, передаваемыми по связи и с достаточной точностью способными заверить, что данное предложение исходит от лица, которое является стороной в договоре [1].

\section{Результаты}

Нормы ГК РФ могут применяться для составления, заключения и исполнения смарт-контрактов. Однако изучив проекты, представленные законодателем на данный момент, можно констатировать, что в них не отражается в полной мере сущность смарт-контрактов и не предоставляются гарантии на его реализацию. Они не направлены на полное раскрытие сути смартконтракта как программного кода и не изучают его функциональную роль в качестве обес- 
печительного обязательства и способа исполнения обязательства одной стороной перед другой. Полагаем, что для полного раскрытия понятия «смарт-контракт» необходимо создать самостоятельный закон, который был бы ориентирован именно на заключение и реализацию «умного договора» и конкретизацию общих норм ГК РФ. Вместе с тем нормы иных специальных законов дополняли бы и корректировали закрепленные этим законом положения в зависимости от сферы хозяйствования и отрасли правового регулирования.

\section{Выводы}

Проведенное исследование позволяет сформулировать следующие выводы.

Смарт-контракт является алгоритмом, предназначенным для автоматизации процесса исполнения контрактов. Иначе его можно определить, как набор правил и последовательность действий для их исполнения. Эти правила изначально хранятся в качестве условий контракта, далее проводится их автоматическая проверка, а затем выполняются условия согласно цифровому протоколу.

В зависимости от объема внесенных данных смарт-контракты подразделяются: на автоматизированные в полном объеме, то есть абсолютно все условия сделки прописаны в программе; автоматизированные частично, то есть одна часть условий прописана в программе, другая - на бумажном носителе.

Кроме того, смарт-контракты классифицируются в соответствии со сферой применения: на контракты в сфере контроля имущественных отношений; финансовые сервисы торговля на бирже, участие в аукционах и др.; исполнение обязательств по различным формам банковских кредитных продуктов в момент наступления событий; социальные сервисы, включая проведение различного рода голосований, выборов, процессы страхования; организацию управления доставкой и хранением продуктов.

Наиболее обоснованным для целей гражданского права будет рассмотрение смартконтракта как формы заключения договора, a не его вида.

Значение этих контрактов прежде всего обусловлено такими преимуществами, как самоисполняемость (главная цель данной технологии); прозрачность сделки (можно отследить все действия по исполнению смарт-контракта); защита от внесения изменений, не утвержденных сторонами; возможность совершения сделок анонимно.

Существенной проблемой является отсутствие законодательного закрепления смарт-контрактов как формы заключения гражданско-правовых соглашений. К числу минусов их использования можно также отнести: смарт-контракты - это программный код, который опосредует возможность ошибок и сбоев в программе, что подразумевает необходимость привлечения специалиста по IT-технологиям и оплату его услуг; до сих пор отсутствует детальное регулирование правоотношений и правоприменительная практика по правовым вопросам, связанные со смартконтрактами (на сегодняшний день приняты только базовые положения); обнаруживается крайне низкий уровень распространенности в России системы смарт-контрактов, поскольку согласно внутреннему регулированию они должны дублироваться на бумажном носителе, что противоречит природе смарт-контрактов, ориентированной на замену бумажного документооборота цифровым.

\section{СПИСОК ЛИТЕРАТУРЫ}

1. Гражданский кодекс Российской Федерации (часть первая) от 30.11.1994 № 51 Ф3 (ред. 23.05.2018) // Собрание законодательства Российской Федерации. - 1994. - № 32. - Ст. 3301.

2. Анищенко, А. Вызов цифровой экономики: смарт-контракты и цифровые права / А. Анищенко // Зуйков и партнеры. - Электрон. текстовые дан. - Режим доступа: https://zuykov.com/ru/about/articles/ 2019/05/20/vyzov-cifrovoj-ekonomiki-smart-kontrakty-icifrovy (дата обращения: 31.05.2019). - Загл. с экрана.

3. Дядькин, Д. С. Смарт-контракты в России: перспективы законодательного регулирования / Д. С. Дядькин, Ю. М. Усольцев, Н. А. Усольцева // UNIVERSUM: Экономика и юриспруденция. -2018 . - № 5 (50). - С. 17-20.

4. Мамаева, Н. В. Смарт-контракты/ Н. В. Мамаев // Наука и образование. - 2018. -№ 4 (27). -С. 11-12.

5. Проект Федерального закона № 419059-7 «О цифровых финансовых активах». - Электрон. текстовые дан. - Режим доступа: https://www.ib.ru/ law/81 (дата обращения: 14.04.2019). - Загл. с экрана. 
6. Проект Федерального закона «Обальтернативных способах привлечения инвестиций (краудфандинге)» : [текст по состоянию на 25.01.2018]. - Электрон. текстовые дан. - Режим доступа: https://www.cbr.ru/ Content/Document/File/48806/20180125_02.pdf(дата обращения: 14.04.2019). - Загл. с экрана.

7. Проект Федерального закона № 419059-7 «О цифровых финансовых активах и о внесении изменений в отдельные законодательные акты Российской Федерации (о цифровых финансовых активах)» : (текст ко второму чтению). - Доступ из справ.-правовой системы «КонсультантПлюс».

8. Проект Федерального закона № 424632-7 «О внесении изменений в части первую, вторую и четвертую Гражданского кодекса Российской Федерации». - Электрон. текстовые дан. - Режим доступа: https://lexfeed.ru/law/424632-7 (дата обращения: 14.04.2019). - Загл. с экрана.

9. Пояснительная записка к проекту федерального закона № 424632-7 «О внесении изменений в части первую, вторую и четвертую Гражданского кодекса Российской Федерации» : [не действует]. Доступ из информ.-правового портала «Гарант.ру».

10. Civil law in the digital economy: analysis of doctrinal adaptation trends / A. O. Inshakova, E. I. Inshakova, A. J. Ryzhenkov, M. V. Sevostyanov/ / Competitive Russia: Foresight Model of Economic and Legal Development in the Digital Age: Proceedings of the International Scientific Conferencein Memory of Oleg Inshakov (1952-2018). Cham : Springer Nature. -2019. - [In print].

11. Kalinina, A. E. Polysubject Jurisdictional Blockchain: Electronic Registration of Facts to Reduce Economic Conflicts / A. E. Kalinina, A. O. Inshakova, A. I. Goncharov // Ubiquitous Computing and the Internet of Things: Prerequisites for the Development of ICT / ed. by E. G. Popkova. Cham : Springer Science + Business Media, 2019. Vol. 826. - P. 205-213. - (Studies in Computational Intelligence).

12. Szabo, N. The Idea of Smart Contracts / N. Szabo. - Electronic text data. - Mode of access: http://szabo.best.net/smart contracts idea.html (date of access: 01.06.2019). - Title from screen.

\section{REFERENCES}

1. Grazhdanskiy kodeks Rossiyskoy Federatsii (chast pervaya) ot 30.11.1994 № 51-FZ : (red. ot 23.05.2018) [Civil Code of the Russian Federation (Part One) Dated November 30, 1994 No. 51-FZ: (As Amended on May 23, 2018)]. Sobraniye zakonodatelstva Rossiyskoy Federatsii [Collection of Legislation of the Russian Federation], 1994, no. 32, art. 3301
2. Anishchenko A. Vyzov tsifrovoy ekonomiki: smart-kontrakty i tsifrovye prava [The Challenge of the Digital Economy: Smart Contracts and Digital Rights]. Zuykov i partnery [Zuikov and Partners]. URL: https://zuykov.com/ru/about/articles/2019/05/20/ vyzov-cifrovoj-ekonomiki-smart-kontrakty-i-cifrovy (accessed 31 May 2019).

3. Dyadkin D.S., Usoltsev Yu.M., Usoltseva N.A. Smart-kontrakty v Rossii: perspektivy zakonodatelnogo regulirovaniya [Smart Contracts in Russia: Prospects of Legislative Regulation]. UNIVERSUM: Ekonomika $i$ yurisprudentsiya [UNIVERSUM: Economics and Jurisprudence], 2018, no. 5 (50), pp. 17-20.

4. Mamaeva N.V. Smart-kontrakty [Smart Contracts]. Nauka i obrazovanie [Science and Education], 2018, no. 4 (27), pp. 11-12.

5. Proekt Federalnogo zakona № 419059-7 "O tsifrovykh finansovykh aktivakh» [The Draft Federal Law No 419059-7 "On Digital of Financial Aassets"]. URL: https://www.ib.ru/law/81 (accessed 14April 2019).

6. Proekt Federalnogo zakona «Ob alternativnykh sposobakh privlecheniya investitsiy (kraudfandinge)» [Draft Federal Law “On Aternative Ways of Attracting Investments (Crowdfunding)"]. URL: https://www.cbr.ru/Content/Document/File/ 48806/20180125_02.pdf(accessed 14 April 2019).

7. Proekt Federalnogo zakona № 419059-7 "O tsifrovykh finansovykh aktivakh $i$ o vnesenii izmeneniy $v$ otdelnye zakonodatelnye akty Rossiyskoy Federatsii (o tsifrovykh finansovykh aktivakh)» [Draft Federal Law No 419059-7 “On Digital Financial Assets and on Amendments to Certain Legislative Acts of the Russian Federation (On Digital Financial Assets)"]. Access from Reference Legal System "KonsultantPlus".

8. Proekt Federalnogo zakona № 424632-7 "O vnesenii izmeneniy $v$ chasti pervuyu, vtoruyu $i$ chetvertuyu Grazhdanskogo kodeksa Rossiyskoy Federatsii» [Draft Federal Law No. 424632-7 “On Amendments to Parts One, Two and Four of the Civil Code of the Russian Federation"]. URL: https:// lexfeed.ru/law/424632-7 (accessed 14 April 2019).

9. Poyasnitelnaya zapiska $k$ proektu federalnogo zakona № 424632-7 «O vnesenii izmeneniy $v$ chasti pervuyu, vtoruyu $i$ chetvertuyu Grazhdanskogo kodeksa Rossiyskoy Federatsii» [Explanatory Note to the Draft Federal Law No. 424632-7 "On Amendments to Parts One, Two and Four of the Civil Code of the Russian Federation"]. Access from "Garant" Informational and Legal Web Portal.

10. Inshakova A.O., Inshakova E.I., Ryzhenkov A.J., Sevostyanov M.V. Civil Law in the Digital Economy: Analysis of Doctrinal Adaptation Trends. Competitive Russia: Foresight Model of Economicand Legal Development in the Digital Age: 
Proceedings of the International Scientific Conferencein Memory of Oleg Inshakov (1952-2018). Cham, Springer Nature, 2019. [In print]

11. Kalinina A.E., Inshakova A.O., Goncharov A.I. Polysubject Jurisdictional Blockchain: Electronic Registration of Facts to Reduce Economic Conflicts. Popkova E.G. ed. Ubiquitous Computing and the
Internet of Things: Prerequisites for the Development of ICT. Cham, Springer Science + Business Media, 2019, vol.826, pp. 205-213. (Studies in Computational Intelligence).

12. Szabo N. The Idea of Smart Contracts. URL: http://szabo.best.net/smart_contracts_idea.html (accessed 1 June 2019).

\section{Information about the Author}

Nizami Elmar ogli Safarli, Postgraduate Student, Department of Civil and Private International Law, Volgograd State University, Prosp. Universitetsky, 100, 400062 Volgograd, Russian Federation, nizami1994@gmail.com, https://orcid.org/0000-0002-4568-5774

\section{Информация об авторе}

Низами Эльмар оглы Сафарли, аспирант кафедры гражданского и международного частного права, Волгоградский государственный университет, просп. Университетский, 100, 400062 г. Волгоград, nizami1994@gmail.com, https://orcid.org/0000-0002-4568-5774 